\title{
Qualidade social e produção do conhecimento $^{1}$
}

\section{Social quality and knowledge production}

\author{
Solange Martins Oliveira Magalhães ${ }^{2}$ \\ Ruth Catarina Cerqueiro Ribeiro de Souza ${ }^{2}$
}

\begin{abstract}
RESUMO
Este trabalho resulta de pesquisa desenvolvida sobre a produção acadêmica de sete instituições organizadas em Rede. Neste artigo apresentamos um recorte referente aos dados das pesquisas sobre professores que se filiaram à abordagem dialética, do Programa de Pós-Graduação em Educação, da Faculdade de Educação, Universidade Federal de Goiás, período de 20082009. Trata-se de uma "pesquisa sobre pesquisas" realizada na perspectiva dialética. Desenvolveu-se uma meta-análise da produção, colocando em foco a questão da qualidade, a partir de sua perspectiva epistemológica e histórica. O grupo busca compreender se e como a produção manifesta a concepção de qualidade; se promove a qualidade mercadológica para a educação, sustentando o pensamento hegemônico e o consenso ativo, ou se promove qualidade social frente às políticas educacionais neoliberais, estruturando o pensamento contra-hegemônico. Articulam-se duas categorias na análise: método e ideário pedagógico. Concluímos que uma parcela dos trabalhos filiados ao materialismo histórico-dialético desenvolve adequadamente o método e o ideário pedagógico, postura que traduz a perspectiva da emancipação. São estudos propositivos, assumem a pesquisa acadêmica como práxis, situam-se contra o consenso ativo e a constituição da hegemonia. Outra parte do recorte analisado apresenta problemas epistemológicos, mesmo sendo os trabalhos filiados à base epistemológica crítica, por não desenvolverem adequadamente o método e construírem o ideário pedagógico na perspectiva neoliberal, o que sustenta a perspectiva hegemônica e o consenso ativo na produção do conhecimento.
\end{abstract}

Palavras-chave: produção acadêmica; professores; qualidade social; consenso ativo.

DOI: $10.1590 / 0104-4060.41257$

1 Pesquisa financiada pelo Conselho Nacional de Desenvolvimento Científico e Tecnológico (CNPQ) e pela Fundação de Apoio à Pesquisa do Estado de Goiás (FAPEG).

2 Universidade Federal de Goiás. Faculdade de Educação. Goiânia, Goiás, Brasil. Rua Delenda Resende de Melo, s/n. Setor Universitário. Caixa postal: 74170030. CEP: 74605050. E-mails: solufg@hotmail.com; ruthcatarina@gmail.com 


\begin{abstract}
This work is the result of a research conducted on the academic production of seven institutions organized in Network. This article presents a clipping with regard to data from research on teachers who joined the dialectic approach of the Post-Graduate Education, Faculty of Education, Goiás Federal University, in the period 2008-2009. It is a "research on research pieces" conducted from a dialectic perspective. We developed a meta-analysis of production, putting into focus the issue of quality, from its epistemological and historical perspective. The group seeks to understand whether and how production expresses the concept of quality; if it promotes the marketing quality for education, sustaining the hegemonic thinking and the active consensus, or if it promotes social quality in the face of neoliberal educational policies, structuring the thought against hegemonic concepts. Two categories are articulated in the analysis: method and teaching ideas. We conclude that a portion of the affiliates works to dialectical historical materialism, properly developing the method and the pedagogical ideas, that is a posture which reflects the perspective of emancipation. These are propositional studies that assume academic research as praxis, lying against active consensus and the establishment of hegemony. Another part of the analyzed crop has epistemological problems, even being affiliated with epistemological critical base, they did not adequately develop the method and they built the pedagogical ideas in the neoliberal perspective, which holds the hegemonic perspective and the active consensus in knowledge production.
\end{abstract}

Keywords: academic production; teachers; social quality; active consensus.

\title{
Problematização
}

O estudo sobre a produção acadêmica do qual resulta este trabalho é realizado por professores pesquisadores, estudantes de graduação e de pós-graduação em educação de sete instituições da Região Centro-Oeste do país. Essas instituições, a saber: Universidade de Brasília (UnB), Universidade Federal de Goiás (UFG), Universidade Federal de Mato Grosso (UFMT), Universidade Federal de Mato Grosso do Sul (UFMS), Universidade de Uberaba (UNIUBE), Universidade Federal de Uberlândia (UFU) e Universidade Federal do Tocantins (UFT), se organizam na Rede de Pesquisadores sobre professores da Região Centro-Oeste/Brasil (Redecentro) há mais de dez anos, para, coletivamente, desenvolverem uma investigação metateórica das respectivas produções acadêmicas. Resumidamente, a Rede tem investido esforços para identificar, catalogar, organizar, realizar a leitura integral dos trabalhos sobre 
professores produzidos em seus programas de pós-graduação em educação, no período de 1999-2014, e analisá-los buscando compreendê-los a partir de suas epistemologias e historicidade.

Um dos objetivos da Redecentro é contribuir para a construção de parâmetros que qualifiquem a produção, no sentido do rigor teórico-metodológico e da relevância social, partilhando da luta que busca uma conotação mais clara para o campo da pesquisa educacional e a validade dos estudos que têm como foco a educação, no caso da temática professores, como ponto de partida e ponto de chegada. O rigor das pesquisas tem um papel essencial que diz como o campo vai se afirmar como científico. A pesquisa educacional, pelo menos aqui no Brasil, enfrenta a dificuldade de ser reconhecida como científica, conformando a necessidade de os pesquisadores da área cuidarem particularmente do rigor e da relevância das pesquisas, vinculando-os com a questão da qualidade.

A articulação entre produção do conhecimento e promoção de qualidade social é aqui pensada a partir do conjunto de elementos e dimensões sócio-históricas, econômicas e culturais, definidores de discursos que incorporam visões de homem, mundo, sociedade, ideário pedagógico, os quais orientam os rumos que a pesquisa deve assumir, seja para um processo de transformação, no sentido da práxis, ou de manutenção das condições de formação, profissionalização e de trabalho docente. A Rede considera importante interrogar para que servem as pesquisas educacionais e quais finalidades da educação se pretende defender com o conhecimento produzido. Entende-se que esse conhecimento favorece a disseminação de discursos das políticas educacionais e pode ajudar a desvelar o sentido político dos projetos sociais, bem como os princípios e objetivos que definem a qualidade da educação.

A investigação metateórica desenvolvida pela Rede pauta-se nos pressupostos teórico-metodológicos da dialética. Conforme exposto, realiza-se a análise da produção dos citados programas, período de 1999-2014. Hoje são cerca de quinhentos trabalhos analisados, entre dissertações e teses, lidos na íntegra, cujos resultados representam as fases desenvolvidas da pesquisa e que têm sido sistematicamente publicados pelos pesquisadores da Rede. (SOUZA; MAGALHÃES, 2013, 2014).

No recorte deste artigo, apresentam-se as análises referentes ao período de 2008-2009, da produção do Programa de Pós-Graduação em Educação, da Faculdade de Educação, da Universidade Federal de Goiás (UFG), colocando-se a temática qualidade no centro das discussões. Esse foco justifica-se porque a questão da qualidade tem sido recorrente na produção acadêmica, sustentando um movimento de convergências e tensões na construção de concepções postas à formação docente, à profissionalização, ao trabalho docente e, ao final, à própria educação. Entende-se que esse movimento gera discursos que tanto 
podem consolidar uma concepção mercadológica de qualidade, o que contribui com a reificação do consenso ativo, com acreditação da Terceira Via (NEVES, 2005, 2013), como podem, ao contrário, sustentar uma concepção de qualidade social contra-hegemônica, que busca desmascarar os princípios mercadológicos aplicados à educação, visando à transformação desta.

Conceitualmente há diferentes concepções de qualidade educacional. Suas diretrizes para a formação, a profissionalização e o trabalho docente se associam a diversas bases epistemológicas e repercutem como consenso nos trabalhos investigativos da área. Nesse sentido, a partir dos trabalhos desenvolvidos pela Redecentro, observou-se a necessidade de se conceituarem indicadores de qualidade social que norteassem a construção de pesquisas sobre professores. Esses indicadores foram estruturados a partir de três abordagens teóricas - a positivista, a materialista histórico-dialética e a fenomenológica. Apesar do recorte, o grupo compreende a emergência de novos paradigmas e já identificou essa presença e suas respectivas abordagens, mas, na atual etapa da pesquisa, a proposta é analisar a produção a partir dos três campos epistemológicos citados, deixando para uma próxima etapa a incorporação e a sistematização de indicadores de qualidade relacionados aos novos paradigmas.

No que se refere à construção dos indicadores de qualidade produzidos, o grupo partiu das seguintes categorias de análise: resumo, objetivos, problemas, justificativas, temas desenvolvidos (formação, profissionalização, trabalho docente), tipo e abordagem de pesquisa, método, ideário pedagógico, referencial teórico-metodológico utilizado. (SÁNCHEZ GAMBOA, 2007). Para cada categoria foram construídos indicadores de qualidade. Aqui, cabe uma ressalva: essa composição não significa que a Rede pretende propor padrões e conceitos generalizadores, estanques, descontextualizados e impostos exteriormente, mas esforça-se no exercício da construção de matrizes conceituais que sejam histórica e politicamente construídas pelos sujeitos pesquisadores, baseadas em critérios e indicadores públicos para a legitimação da qualidade social. (DIAS SOBRINHO; DIAS, 2006). Trata-se também da explicitação de um posicionamento político, como pesquisadoras e formadoras de professores na universidade pública. Concordamos com Santos (2012, p. 262) sobre a importância das recomendações da "Declaración de San Miguel de Tucumán", que indica a necessária oposição ao modelo neoliberal imposto à universidade, logo, ao campo da pesquisa, para que a busca da qualidade desligue-se de critérios que vinculem valores de mercado como seus indicadores. Isso nos associa aos autores que se propõem a repensar um novo caminho para a produção do conhecimento na universidade, a fim de que ela seja construída contextualizada local, regional e nacionalmente e não imposta desde modelos externos mercadológicos. 
Para tanto, neste trabalho, recorre-se ao diálogo com a literatura atual sobre a temática para traçar um percurso metodológico fundamentado no método dialético, nos posicionamentos epistemológico, ético-político, ontológico e gnosiológico correspondentes. Buscou-se nos discursos produzidos nas dissertações e teses apreender o que os autores constroem como sentido de qualidade. Isso envolveu identificar seus aportes teóricos, concepções e posicionamentos políticos, mesmo que nem todos os autores tenham construído indicadores da qualidade social, essa análise foi articulada à arquitetura construída pela Rede.

Discute-se ainda a relação entre a qualidade e consenso ativo, como estratégia ideológica estruturante da Terceira Via no campo da produção do conhecimento, formação, profissionalização e trabalho docente, como percurso necessário à deliberação de qualidade educacional. Em seguida, articula-se a análise dos discursos da produção acadêmica sobre professores, do Programa de Pós-Graduação em Educação da universidade citada, destacando-se as categorias de análise método e ideário pedagógico. Nessa articulação, busca-se identificar e compreender se e como as posições epistemológicas, o posicionamento político e metodológico das pesquisas da citada instituição têm lidado com a legitimação das ideias neoliberais ou a resistência a elas, no que se refere à qualidade proposta à educação, a partir de sua epistemologia e historicidade.

\section{Concepção de qualidade $x$ consenso ativo: estratégia ideológica de políticas de Terceira Via e sua presença no campo da pesquisa acadêmica}

A construção da concepção de qualidade que perpassa o campo de estudos dos programas de pós-graduação em educação da região Centro-Oeste/Brasil tem bases estruturadas na historicidade da trajetória do movimento educacional, instituída pelo Estado brasileiro. Destaca-se a década de 1990, quando o campo passou por reformas para aderir aos princípios do neoliberalismo, concretizados nas políticas e programas, que, desde então, passaram a governar a educação, inclusive definindo novas diretrizes e metas para o campo da pós-graduação.

Tal movimento respondia à reestruturação produtiva do Estado, acarretando desdobramentos particulares para a produção do conhecimento. Na busca pelo equacionamento dos problemas que surgiram frente a um novo modelo de gestão pública posta ao campo da pesquisa e da educação, impôs-se ao campo bases gerencialistas como estratégia para melhor administrar as novas finalidades requeridas à educação em geral e à Educação Superior em particular, transfor- 
mando-se suas finalidades para atender aos interesses do mercado capitalista. No que se refere à universidade pública, por exemplo, destituem-se suas finalidades, que são a busca pelo conhecimento e pela ciência e a formação omnilateral, e estabelecem-se finalidades de aquisição e reprodução de conhecimentos que sirvam aos interesses econômicos. Como afirma Dias Sobrinho (2012), essas transformações atuam no sentido de construir o consenso sobre um conceito de qualidade neoliberal que despreza os significados sociais da formação humana.

Esse novo modelo de gestão intrumentalizou-se com mecanismos reguladores, cuja finalidade foi contribuir para a construção do consenso ativo. (SHIROMA; SANTOS, apud EVANGELISTA, 2014a). O consentimento ativo faz parte das estratégias das classes dominantes para se tornarem também classe dirigente, seja pela coerção seja pelo consenso, mas sempre assumindo a direção intelectual e moral do processo social. Faz-se necessário destacar que o consenso é fundamental para a constituição da hegemonia, sendo parte do processo de regulação que se utiliza de mecanismos de avaliação para se consolidar. Esses mecanismos valem-se de padrões e "rankings" explicitados para promoverem sua aceitação entre sujeitos, que, convencidos, passam a aprovar as políticas propostas, em sua grande maioria, sem questionamentos, concretizando-as em suas ideias e práticas. Por isso mesmo, fundamenta-se uma nova sociabilidade que envolve professores, alunos, dirigentes educacionais, pais, comunidade, em um mesmo projeto social, no caso, o neoliberal.

Quanto à produção acadêmica, considera-se que em seu desenvolvimento as pesquisas incorporam e refletem essas dimensões macro e micro das políticas educacionais, ou para aderir a elas, a partir da acreditação do modelo neoliberal, ou para a elas resistir, assumindo, assim, a construção contra-hegemônica. Shiroma e Santos (apud EVANGELISTA, 2014a) acrescentam que o consenso ativo se fortalece pela criação e disseminação de uma gama de conceitos que são aceitos pela sociedade, como, por exemplo: a necessidade de participação, eficiência, eficácia, concepções, compreendidas com a mesma lógica regulatória e que passam a representar os indicadores de uma concepção de qualidade mercadológica e hegemônica para a educação.

Esse significado mercantilista de qualidade foi criado e difundido pelo Banco Mundial, Unesco e Organismos Internacionais, que produziram documentos que acabaram se tornando governamentais. Para essas organizações, os indicadores de qualidade propostos reduzem a educação a dados quantitativos, garantindo, a partir dos resultados obtidos, a reconversão da função social da escola, da educação, do professor. Dessa maneira, subtraí-lhes a relevância social, limitando-os à atividade técnica, desligada da sua dimensão política, ética, estética e cultural. (MAGALHÃES; SOUZA, 2012, 2014). 
Ainda é necessário considerar que a estratégia é sustentada para conter as crescentes ondas de resistência e negação às políticas neoliberais postas à educação. A ideia principal é revestir as políticas implantadas com uma face "mais humana", cujo principal objetivo foi e continua sendo reinventar a eficiência econômica do capitalismo, dando-lhe roupagem de "justiça social". Para tanto, retiram-se alguns aspectos das ideias sociais democráticas, presentes nas lutas, conquistas e direitos sociais, principalmente aquelas que poderão ajudar na manutenção e ampliação do status quo. Na educação, essas ideias democráticas estão presentes na forma de slogans - que solicitam qualidade, competência, habilidades, etc. - e nas políticas de Terceira Via e são caracterizadas, por exemplo, pelo voluntariado, pela filantropia e, sobretudo, pela redução das demandas sociais ao nível corporativo dos interesses particulares e pelo processo de despolitização da política. Já no campo da produção acadêmica, essas ideias se fazem acompanhar pela exigência do aumento quantitativo da produção, com vista ao atendimento do mercado, o que também tem gerado seu recuo teórico (MORAES, 2001), quer seja pelo seu expressivo contingente, quer seja pela influência que essa produção passou a exercer na conformação técnica, ética e política dos profissionais em geral e da educação.

Desse modo, a produção do conhecimento ganha centralidade e relevância estratégica nos dias atuais. Seu controle é fortemente exercido a partir dos critérios de financiamento para pesquisas, por exemplo, ou a partir da imposição do caráter competitivo entre os pesquisadores. As exigências do conhecimento ancoram-se no paradigma neoliberal, que atribui-lhe sentido utilitarista e objetivos que alimentam as prioridades das atuais políticas educativas. Essas exigências, assumidas por um grupo de pesquisadores nas nossas universidades, têm provocado a reação de outros que as denunciam como constrangimento à autonomia do trabalho científico, cujo objetivo é atender ao apelo para maior aproximação das finalidades científicas às finalidades políticas, a fim de orientar e influenciar a produção científica e as práticas pedagógicas.

Assim entendendo, o conhecimento acadêmico pode atuar como instrumento de regulação, na medida em que sua produção e disseminação participa da formação da intelectualidade brasileira, podendo dar sustentação às decisões de políticas educativas e à lógica que as legitima. Também merece registro outra forma de controle da produção acadêmica que se explicita na maneira como os pesquisadores se adaptam às temáticas "aconselhadas", com suas epistemologias e ontologias, conforme demandadas pelos mesmos interesses políticos, com o objetivo de sustentar as reformas na área. (VISEU, 2014). Entende-se que há o empresariamento do conhecimento na pós-graduação em educação, formatado para sustentar a ampliação e renovação do capitalismo. 
Nesse sentido, foram induzidas importantes mudanças, tanto na formação, na profissionalização, no trabalho docente, como na produção do conhecimento que, na grande maioria, passou sistematicamente a difundir o ideário hegemônico como critério de qualidade da educação. Conforme o entendimento da Rede, os conteúdos dos discursos presentes na produção acadêmica estão, muitas vezes, respondendo à tutela da ideologia neoliberal, e quando assim o fazem fortalece-se a legitimação de forte componente ideológico à educação, considerados como cenários de desenvolvimento e expansão do conteúdo ideológico da Terceira Via na produção do conhecimento acadêmico.

No caso da produção acadêmica sobre professores do Centro-Oeste, é possível identificar a importância dada aos docentes para a implantação dos projetos políticos neoliberais sociais, o que também implica analisar se os mesmos não estão sendo associados às políticas de Terceira Via. (MAGALHÃES; SOUZA, 2012, 2014). As autoras mostram que em grande parte da produção gerada no período de 1999-2005 foram divulgadas e reproduzidas ideias que sistematizavam a acreditação das demandas originadas nas políticas educacionais neoliberais de avaliação, controle e financiamento, quer seja dos professores quer seja da educação, conforme analisou Dias Sobrinho (2004, 2008).

A política de avaliação e financiamento, regulada pelas agências de fomento como a Coordenação de Aperfeiçoamento de Pessoal de Nível Superior (CAPES), gera contradições entre os pesquisadores. Enquanto alguns são favoráveis e até reforçam as normas impostas, outros questionam os padrões colocados à produção do conhecimento, sua lógica de avaliação quantitativa, sua indução de critérios meritocráticos, alegando seu distanciamento de uma avaliação que representaria efetivamente a melhoria da qualidade da produção do conhecimento qualitativamente e da educação em termos de bem comum.

O que se percebe é o empobrecimento epistemológico consequente de tal política, destacando-se que os aspectos impostos comprometem o rigor teórico e a relevância social da maioria das pesquisas. (SOUZA; MAGALHÃES, 2014). Também reforçam uma concepção de qualidade relacionada à mercantilização da educação que é acreditada e reafirmada por um grupo de intelectuais orgânicos hegemônicos neoliberais, no movimento de apropriação do discurso crítico. Isso tem gerado muitos embates entre os pesquisadores que se associam a diferentes perspectivas teóricas, as quais fundamentam suas posições e suas concepções, inclusive a de qualidade, quer seja como social, voltada para o bem público, quer seja como mercadológica, favorável aos interesses do capital. (CUNHA; PINTO, 2009; SOUZA; MAGALHÃES, 2013, 2014).

Nesses termos, realça-se ainda mais o papel estratégico da produção acadêmica, pois, no conjunto, pode promover a difusão dos discursos indutores de conformismo na formação da intelectualidade brasileira, contribuindo para 
a internalização de princípios e valores que objetivam gerar uma concepção de qualidade que não referenda projetos sociais em seu sentido ético-político.

Portanto, tem-se que os mesmos mecanismos ideológicos neoliberias historicamente constituídos marcam a produção acadêmica. Somam-se as preocupações dos pesquisadores da Rede às manifestadas por Gatti (2001), Kuenzer e Moraes (2005), Souza e Magalhães $(2013,2014)$ sobre a produção acadêmica. No conjunto de suas reflexões, essas autoras alertam para o fato de que as fragilidades das bases epistemológicas e a ausência de posicionamento ético-político mostram que a inadequação epistemológica presente nas pesquisas faz com que não cumpram a função de desalienação, emancipação e, utopicamente, de transformação social.

Em análise de uma década da produção acadêmica do Centro-Oeste sobre professores, período de 1999-2009, Souza e Magalhães $(2013,2014)$ advertem sobre a dispersão teórica e metodológica, que causa um sincretismo teórico. Verificam que, em muitos casos, os pesquisadores dividem-se entre a assunção da epistemologia da prática e a epistemologia da práxis, e que, quando da primeira, observam-se respostas positivas à proposta hegemônica (GRAMSCI, 1989), bem como o afastamento da compreensão sócio-histórica, comprometendo, portanto, o objetivo de emancipação e de transformação social.

\section{Princípios e fundamentos da epistemologia geral: aspectos norteadores do estudo da Redecentro}

Por epistemologia entende-se o estudo das possibilidades, legitimidade, valor e limites do conhecimento científico; trata-se do "modo de pensar o logos". A partir de uma base paradigmática, a perspectiva epistemológica define uma racionalidade ou estruturas conceituais prévias, cujos princípios dizem como são sustentadas as ideias orientadoras da produção do conhecimento. A perspectiva epistemológica age como guia orientador da produção do conhecimento e também como estruturante do posicionamento epistemológico ou metódico, este sempre vinculado às correntes teóricas próprias de um determinado campo teórico.

Numa ordem didática, a consistência, a coerência e a relevância da produção do conhecimento também exigem posicionamento político, que representa a forma como o teórico (ou pesquisador) compreende a realidade, os modos de construí-la e, em termos de reflexividade epistemológica, associa-se ao como pretende modificá-la. $\mathrm{O}$ posicionamento político também está relacionado ao 
modo como o pesquisador compreende a ciência, como se posiciona em relação a ela, como direciona o seu fazer. Tal posicionamento, em proximidade à dimensão ontológica, se converte em posicionamento ético-político, pois passa a sustentar o modo como o pesquisador compreende o ser humano e sua realidade.

Há ainda o enfoque metodológico, que diz sobre o modo de construção da ciência (ou da pesquisa), que também ocorre a partir da perspectiva epistemológica e do posicionamento ético-político. Afinal, não há metodologia neutra. A coerência interna da produção do conhecimento exige construções metodológicas consistentes que ajudem a percorrer o caminho escolhido, as quais vão dizer como se percebe, analisa, compreende e se interfere no objeto de estudo, ou seja, na própria realidade.

Com base nesse entendimento, afirma-se que os estudos que não apresentam perspectiva epistemológica, posicionamento epistemológico ou metódico, posicionamento ético-político e adequado enfoque metodológico, resultam em dispersão teórica ou níveis epistemológicos superficiais na elaboração das pesquisas, o que, conforme Souza e Magalhães $(2013,2014)$, denota fragilidade ou pobreza teórica.

A fragilidade epistemológica pode ocorrer nas diferentes bases teóricas, mas em qualquer campo gera posturas a-teóricas associadas a relativismos ou a modismos epistemológicos. Essas posturas, segundo Tello e Mainardes (2015, p. 163), fazem com que a produção do conhecimento desvie-se da "reflexividade ética", o que inclui desconstruir sentidos sobre a realidade e implica o não esclarecimento do posicionamento ético-político do pesquisador. No campo da produção do conhecimento alguns problemas epistemológicos têm sido associados às pesquisas descritivas, ou crítico-reprodutivistas, ou interpretativas que dizem muito pouco sobre o que e como pretende transformar o sujeito social e sua realidade. No conjunto da obra de autores como Mello (1983), Saviani (2013), Souza e Magalhães (2014), Tello e Mainardes (2015), encontra-se o questionamento, de forma cada vez mais incisiva, sobre aspectos do conhecimento construído pelos pesquisadores, tais como a qualidade que sustenta a educação, as proposições voltadas para o campo educacional, as epistemologias que as orientam, como, por exemplo, a epistemologia da prática e a epistemologia da práxis. Essas epistemologias destacam princípios que geram diferentes impactos no que se refere à qualidade da educação. No caso da primeira, ajuda a alicerçar as estratégias do neoliberalismo que objetiva o desenvolvimento educacional voltado ao mercado; no caso da segunda, busca-se desmascarar e transformar o modo pelo qual a hegemonia se manifesta, por meio de princípios que visam um padrão de qualidade social na educação.

A Redecentro, inspirada no diálogo construído com os diferentes autores até aqui citados, analisa a produção acadêmica, articulando as categorias de 
análise construídas, buscando compreender o conhecimento produzido sobre professores e a qualidade de educação explicitada nas pesquisas.

Neste artigo, busca-se refletir sobre a produção, articulando dialeticamente, na trajetória metodológica, duas categorias: método e ideário pedagógico - concepção de educação e de escola. Na análise, busca-se estruturar: a) conceituação; b) explicitação de intencionalidade; c) posicionamento político do autor; d) percurso metodológico proposto; e) tema desenvolvido; f) resumo elaborado; g) construção de objetivos; h) conclusão, e i) referencial teórico-metodológico assumido. Essa articulação carrega em si os aspectos ontológicos, gnosiológicos, axiológicos, lógicos, que ajudam a compor a base epistemológica desenvolvida no corpo da pesquisa. (SOUZA; MAGALHÃES, 2014).

A produção analisada refere-se ao período de 2008-2009, do Programa de Pós-Graduação em Educação, da Faculdade de Educação, Universidade Federal de Goiás. No período, foram defendidas 54 dissertações e 20 teses. Do total de 74 trabalhos, 14 versam sobre a temática professores. Todos os $14 \mathrm{se}$ pautaram no materialismo histórico-dialético e serão nosso objeto de análise, uma vez que representam a totalidade dos trabalhos no que se refere à base epistemológica assumida.

A categoria método desenvolvida na análise é sustentada no grupo a partir de três bases epistemológicas - a positivista, a fenomenologia e o materialismo histórico-dialético. No caso do materialismo histórico-dialético, ela é composta por oito indicadores de qualidade social, a saber: 1) abordar o objeto na perspectiva histórica, a partir de suas origens; 2) buscar na história as origens do problema, do todo e não de tudo; 3) trabalhar com os sujeitos típicos a serem pesquisados; 4) apresentar o concreto pensado, evidenciando o objeto que estava oculto, o movimento dialético; 5) utilizar categorias marxistas para análise trabalho, alienação, ideologia, classe social, contradição, negação, totalidade, universalidade; 6) articular teoria e prática e denominá-la práxis; 7) apresentar os dados, evidenciando seus nexos internos e contraditórios com a totalidade; 8) referencial teórico utilizado.

A partir desses indicadores, pode-se afirmar que em 100\% dos trabalhos do recorte, o método foi explicitado; contudo, há fragilidades epistemológicas em seu desenvolvimento, como a construção dos indicadores 4, 5 e 6 . A análise mostra que em $40 \%$ dos trabalhos, apesar do esforço e da tentativa, os pesquisadores não conseguiram desenvolver os indicadores. Isso leva a constatar que, entre outras consequências, as pesquisas não se estruturaram como práxis.

A base teórica utilizada foi acrítica, com destaque aos autores: T. Adorno, G. Frigotto, A. Gramsci, J. Habermas, H. Marcuse, K. Marx, D. Saviani, P. Freire. Essas referências aparecem em outros períodos (1999-2005) analisados pela Rede. (SOUZA; MAGALHÃES, 2014). Ainda no que se refere ao refe- 
rencial teórico, no período analisado não foi identificado o referencial teórico-metodológico.

Seguindo os passos metodológicos da Rede, articulou-se a categoria método com a categoria ideário pedagógico, com destaque para a composição das concepções de educação e de escola. Assim como na categoria método, os indicadores dessa categoria resultaram da síntese integradora dos pensamentos de Limoeiro (1991), Cury (1995), Freire (1997), Saviani (1991), Mészáros (2008), Sánchez Gamboa (2007). A concepção de educação, nessa perspectiva, é compreendida como processo social, científico, de hominização, voltada para a construção do homem coletivo, político, com liberdade histórica, concreta. E a concepção de escola busca a realização de autonomia, é lugar de politização do exercício da cidadania. No instrumento de análise desenvolvido pelo grupo, a concepção de escola apresenta o seguinte indicador de qualidade social:

A escola é parte inseparável da totalidade social, e como tal, apresenta as mesmas situações de reprodução e de mudança que caracterizam aquela totalidade. Representa uma possibilidade de ruptura e transformação da sociedade ao proporcionar a construção do conhecimento emancipador. (Parte do Instrumento de análise da Redecentro. SOUZA; MAGALHÃES, 2014).

A partir dos indicadores construídos, identificou-se que o ideário pedagógico era crítico (95\%). Em análise articulada ao referencial teórico utilizado e à categoria método, contraditoriamente, percebeu-se que, em $40 \%$ dos trabalhos, havia a indistinção entre proposições referendadas numa epistemologia crítica e numa instrumental. Essa postura refletiu a fragilidade epistemológica de parte da produção, pois os pesquisadores não diferenciaram epistemologias, ao recorrerem a autores que se filiam à epistemologia da prática e a autores que se filiam à epistemologia da práxis, como se esses defendessem a mesma coisa. Isso pode ser exemplificado na construção das concepções de escola, educação, professor. Apesar de se afirmarem críticos, recorreram a Schön, Perrenoud, Torres, Tardif, Tedesco e Fanfani, para a construção dessas concepções. Ao assim procederem, justificam, com estes autores, um tipo de qualidade mercadológica à educação.

Pensando na totalidade dos estudos analisados, os pesquisadores denominam-se críticos, mas, devido a fragilidades epistemológicas, constroem conceitos contraditórios, conforme trechos abaixo, nos quais mostram que assumem o discurso neoliberal, por filiação ou ingenuidade, ao enfatizar, por exemplo, a responsabilização do professor por toda mudança educacional e social e seu êxito. 
[...] Podemos afirmar que, implicitamente, a proposta de ciclos determina mudanças significativas no trabalho realizado pelo professor e que caberá a ele incorporar as mudanças em todo o processo educacional e na sua atuação em sala de aula. Nos ciclos, o trabalho docente é realizado pelo coletivo de professores, que se torna responsável não só pelas mudanças necessárias, inclusive as curriculares, como também pela própria continuidade da proposta. (Trecho de trabalho analisado, número 119, p. 111, grifos nossos).

[...] Uma reflexão no sentido de ter nesse país uma educação de qualidade, capaz de superar os modelos atuais que, muitas vezes, atendem mais interesses políticos e econômicos do que educacionais e sociais. Uma educação que não basta universalizar, mas é preciso romper as barreiras da exclusão, do preconceito, da falácia política e oferecer condições de sucesso e permanência para o aluno, sem perder de vista a qualidade para todos. Para tanto, faz-se necessário que a formação inicial do professor seja levada a sério e que o professor tenha condições de investir em sua formação continuada e que, acima de tudo tenha condições de trabalho. (Trecho de trabalho analisado, número 113, p. 154, grifos nossos).

A análise mostra que a construção de conceitos relacionados à epistemologia da prática atribui ao professor poderes desproporcionais, oriundos apenas de seu trabalho individual e de sua dedicação a ele. Segundo Evangelista e Triches (2014b, p. 67), nesse caso, ele tende ser tomado como um "superprofessor", cujas excessivas atribuições não encontram correspondência nem em sua formação nem em suas "condições de trabalho". Para as referidas autoras, o superprofessor é destacado num processo de reconversão profissional, para assumir a função social neoliberal do novo professor, isso é, ser multifuncional, polivalente, responsável, flexível, adepto das tecnologias, inclusivo, tolerante.

Ainda segundo as autoras, a reconversão do "ser professor" influi diretamente na desconstrução de sua identidade e na construção de consenso ativo sobre uma nova identidade neoliberal do docente. Nesse sentido, aqueles $40 \%$ dos trabalhos analisados sobre a categoria ideário pedagógico mostram uma contradição, pois, apesar de assumirem a intencionalidade de desenvolver o método dialético na construção das pesquisas, acabam referendando um ideário pedagógico neoliberal. A Rede analisa que, por modismo ou despreparo, acabam contribuindo para a acreditação de uma qualidade neoliberal, reforçando na educação uma pedagogia da hegemonia. (NEVES, 2013).

No há como desconsiderar, no movimento da dialética, a existência de trabalhos que contradizem a lógica neoliberal. Entre os 14 que se filiaram à 
dialética, dois sustentavam a perspectiva crítica contra-hegemônica na construção do ideário pedagógico. Esses eram trabalhos propositivos, identificavam o posicionamento ético-político do autor que o situava contra o consenso ativo e a constituição da hegemonia. No conjunto, essas duas pesquisas, fundamentadas no materialismo histórico-dialético, responderam aos requisitos de qualidade social perseguidos pela Rede na construção do conhecimento.

\section{Algumas articulações dialéticas para finalizar}

Um dos objetivos da Redecentro é contribuir para a produção de um conhecimento que visa à melhoria da educação local, regional e nacional com a construção de parâmetros que qualifiquem o sentido de qualidade social das pesquisas. Nesse sentido, destaca-se a importância da "vigilância epistemológica" sustentada pelo grupo por meio dos indicadores de qualidade social da produção acadêmica sobre professores para que não assumam uma postura estruturadora das políticas de "Terceira Via".

Retomando o objetivo principal deste artigo, propusemos identificar e compreender se e como as posições epistemológicas, o posicionamento político e metodológico das pesquisas da citada instituição, têm lidado com a legitimação ou a resistência a ideias neoliberais, no que se refere à qualidade proposta para a educação, a partir de sua epistemologia e historicidade. Pode-se afirmar, com apoio na posição epistemológica da Rede, que, em termos de qualidade social, não basta apenas declarar a intencionalidade metódica, bem como defender posicionamentos epistemológico, metodológico e político críticos; faz-se necessário que o trabalho apresente coerência interna, quer seja na construção teórica e no desenvolvimento do trabalho, na assunção de concepções claras, com bases teóricas e metodológicas explícitas e adequadas, quer seja na construção de um movimento que expresse o engajamento do pesquisador no processo de contestação e superação do movimento hegemônico ativo, firmando bases emancipadoras na formação de outros pesquisadores e professores.

No que se refere à qualidade proposta para a educação, a partir de sua epistemologia e historicidade, dois trabalhos apresentam adequação metódica coerentes na construção do ideário pedagógico, considerando os indicadores propostos pela Rede. Entretanto, 12 deles ainda alicerçam o movimento de construção da "Nova Pedagogia da Hegemonia", por duas vias: 1) sustentam conceitos relacionados ao ideário pedagógico que ensinam, divulgam, consolidam práticas que correspondem aos princípios hegemônicos; 2) promovem um 
discurso de aparência crítica, mas, suas bases teóricas, contraditoriamente, se fundam nos mesmos princípios ideológicos que representam a Terceira Via. Essa análise ajuda a alertar os pesquisadores da citada instituição para a necessidade da vigilância epistemológica, se se pretende não legitimar ideias neoliberais no que se refere à qualidade proposta para a educação.

Estar vigilante implica, entre outros critérios, estabelecer e assumir posicionamento teórico-metodológico claro para a produção do conhecimento, o que, consequentemente, requer a introdução da dimensão crítica, do rigor nas metodologias e nos métodos de trabalho, explicitação no método de exposição de como as concepções foram construídas e referendadas. Significa a prática de atitudes críticas e éticas, que devem funcionar como radar permanente para os pesquisadores, pois, segundo a análise da Redecentro, tais atitudes parecem necessitar ser mais bem cultivadas no âmbito da produção acadêmica para que a produção do conhecimento sobre professores possa se desenvolver no confronto com imposições hegemônicas e na construção de caminhos contra-hegemônicos.

Assim, exige-se que os pesquisadores mostrem-se atentos para não engrossarem a fileira dos que defendem a qualidade da educação a partir de slogans, prontos a serem usados e divulgados em qualquer perspectiva de trabalhos educacionais, conforme Shiroma e Santos (apud EVANGELISTA, 2014a) pontuam. Construir sentidos e significados emancipadores sociais, éticos e políticos no trabalho investigativo, sobretudo, no que concerne à função social dos professores, pode ser um aspecto das mudanças necessárias frente aos princípios neoliberais dominantes no campo da produção do conhecimento e da educação. Espera-se, numa perspectiva emancipadora, que os pesquisadores se unam na discussão para superação da reprodução de discursos alienantes presentes no campo da pesquisa acadêmica sobre professores.

Outras abordagens epistemológicas ou teorias ligadas a paradigmas emergentes se fazem presentes e crescentes na produção da Região; embora não tenham feito parte do recorte analisado, não se nega sua importância. Em análise futura, pretende-se construir seus indicadores de qualidade, atentando para o mesmo cuidado com as questões aqui discutidas.

Para finalizar, resgatamos o alerta de Freire em sua clássica obra Pedagogia da Autonomia (1997), ao afirmar que a emancipação exige levar os sujeitos pesquisadores a fazer a leitura do mundo, mas que, para fazê-la, é necessário recorrer ao conhecimento socialmente produzido e acumulado, pois esse conhecimento é a lente que permite enxergar para além do fato, identificar seus condicionantes, num processo que se constrói em arquitetura sólida e sistematizada. 


\section{REFERÊNCIAS}

CUNHA, Maria Isabel; PINTO, Marialva Moog. Qualidade e educação superior no Brasil e o desafio da inclusão social na perspectiva epistemológica e ética. Revista Brasileira de Estudos Pedagógicos, v. 90, n. 226, 2009.

CURY, Carlos Roberto Jamil. Educação e Contradição: elementos metodológicos para uma teoria crítica do fenômeno educativo. 6. ed. São Paulo: Cortez-Autores Associados, 1995.

DIAS SOBRINHO, José. Avaliação ética e política em função da educação como direito público ou Como mercadoria? Educ. Soc., Campinas, v. 25, n. 88, n. especial, p. 703725 , out. 2004.

DIAS SOBRINHO, José. Avaliação da educação superior: avanços e riscos. EccoS Revista Científica, São Paulo, v. 10, n. especial, p. 67-93, 2008.

DIAS SOBRINHO, José. Políticas y conceptos de calidad: dilemas y retos. Avaliação, Campinas; Sorocaba, SP, v. 17, n. 3, 2012.

DIAS SOBRINHO, José; DIAS, Rafael de Brito. Acreditação da educação superior e C\&T: políticas e ideologia. Avaliação, Campinas; Sorocaba, SP, v. 11, n. 4, 2006.

EVANGELISTA, Oneida. O que revelam os slogans na política educacional. São Paulo: Junqueira e Marin Editores, 2014a.

EVANGELISTA, Oneida; TRICHES, Josemara. Professor: A profissão que pode mudar um país? In: EVANGELISTA, O. O que revelam os slogans na politica educacional. São Paulo: Junqueira e Marin Editores, 2014b.

FREIRE, Paulo. Conscientização e alfabetização: uma nova visão do processo. In: FREIRE, P. Pedagogia da autonomia. Rio de Janeiro: Paz e Terra, 1997.

GATTI, Bernadetti Angelina. Implicações e perspectivas da pesquisa educacional no Brasil contemporâneo. Cadernos de Pesquisa, n. 113, p. 65-81, jul. 2001.

GRAMSCI, Antônio. Concepção dialética da história. 8 ed. Rio de Janeiro: Civilização Brasileira, 1989.

GRAMSCI, Antônio. Os intelectuais e a organização da cultura. Tradução de Carlos Nelson Coutinho. 8. ed. Rio de Janeiro: Civilização Brasileira, 1991.

KUENZER, Acácia Zeneida; MORAES, Maria Célia Marcondes de. Temas e tramas na pós-graduação em educação. Educ. Soc. [on-line], v. 26, n. 93, p. 1341-1362, 2005.

LIMOEIRO, Mirian. O mito do método. In: ASSOCIAÇÃO DOS GEÓGRAFOS BRASILEIROS. Boletim Carioca de Geografia. 6. ed. São Paulo: Cortez, 1991.

MAGALHÃES, Solange M. O.; SOUZA, Ruth Catarina C. R. de. A Questão do Método e da Metodologia: uma análise da produção acadêmica sobre professores(as) da Região Centro-Oeste/Brasil. Educ. Real., Porto Alegre, v. 37, n. 2, p. 669-693, maio/ago. 2012. 
MAGALHÃES, Solange M. O.; SOUZA, Ruth Catarina C. R. de. Vigilância epistemológica na pesquisa acadêmica sobre professores. In: SEMINARIO DE LA RED ESTRADO. Derecho a la educación, políticas educativas y trabajo docente en América Latina: experiencias y propuestas en disputa, X., 2014, Salvador. Anais... Salvador, 2014.

MELlO, Guiomar N. de. Pesquisa educacional do Brasil. Caderno de Pesquisa, São Paulo, n. 46, p. 67-82, 1983.

MÉSZÁROS, Ivan. Para além do Capital. São Paulo: Boitempo, 2008.

MORAES, Maria Célia M. de. Recuo da Teoria: dilemas na pesquisa em educação. Revista Portuguesa de Educação, Braga, v. 14, n. 1, p. 7-25, jan./jun. 2001.

NEVES, Lucia Haria Wanderley (Org.). A nova pedagogia da hegemonia: estratégias do capital para educar o consenso. São Paulo: Xamã, 2005.

NEVES, Lucia Haria Wanderley. O professor como intelectual estratégico na disseminação da nova pedagogia da hegemonia. In: REUNIÃO NACIONAL DA ANPED, 36. 2013, Goiânia, GO. Anais... Goiânia, GO, 2013.

SÁNCHEZ GAMBOA, Silvio. Pesquisa em Educação: lógicas e epistemologias. Chapecó: Argos, 2007.

SANTOS, Margareth Guerra dos. As redes de agências de avaliação da qualidade e acreditação da educação superior na América Latina: Rana e Riaces. In. LEITE, Denise; FERNANDES, Cleoni Barboza. (Orgs.). Qualidade da educação superior: avaliação e implicações para o futuro da universidade. Porto Alegre: EDIPUCRS, 2012. p. 261-269.

SAVIANI, Demerval. Pedagogia histórico-crítica: Primeiras aproximações. São Paulo: Cortez: Autores Associados, 1991.

SAVIANI, Demerval. Epistemología de las políticas educativas: algunas precisiones conceptuales. In: TELLO, C. (Org.). Epistemologías de la política educativa: posicionamientos, perspectivas y enfoques. Campinas: Mercado de Letras, 2013.

SHIROMA, Eneida; SANTOS, Fabiano Antônio dos. Slogans para a construção do consentimento ativo. In: EVANGELISTA, O. O que revelam os slogans na política educacional. São Paulo: Junqueira e Marin Editores, 2014.

SOUZA, Ruth Catarina C. R. de; MAGALHÃES, Solange M. O. Implicações da opção metodológica pelo materialismo histórico dialético na produção acadêmica do Centro-Oeste/Brasil. Revista Interação, Faculdade de Educação - UFG, Goiânia, v. 38, n. 1, 2013.

SOUZA, Ruth Catarina C. R. de; MAGALHÃES, Solange M. Pesquisa sobre Professores(as): Métodos, Tipos de Pesquisas, Temas, Ideário Pedagógico e Referenciais teóricos. 2. ed. Goiânia: Editora Puc-Goiás, 2014. p. 37-68.

TELLO, Cesar; MAINARDES, Jefferson. Revisitando el enfoque de las epistemologías de la política educativa. Práxis Educativa, Ponta Grossa, v. 10, n. 1, p. 153-178, jan./ jun. 2015. 
VISEU, Sofia. Educ. Soc., Campinas, v. 35, n. 127, p. 491-508, abr./jun. 2014. Disponível em: <http://www.cedes.unicamp.br>. Acesso em: 20 out. 2015.

Texto recebido em 11 de maio de 2015. Texto aprovado em 11 de outubro de 2015. 